\title{
A LEITURA TRADUTÓRIA DO TEXTO CIENTÍFICO SOB O EFEITO DE ESTRESSE LABORAL: PERSPECTIVAS DE INVESTIGAÇÃO
}

Fabiano Bruno Gonçalves é professor-bolsista do Instituto de Letras/UFRGS; doutorando em Estudos da Linguagem na UFRGS; tradutor; bolsista CAPES/REUNI. E-mail: fabiano.bg@gmail.com

Maria José Bocorny Finatto é professora do Instituto de Letras/UFRGS; pesquisadora do Grupo TERMISUL; coordenadora do grupo GELCORP-SUL; bolsista PQ CNPq. E-mail: mariafinatto@gmail.com

\begin{abstract}
Resumo
Apresentam-se perspectivas para investigar efeitos psicofisiológicos no processo de leitura e produção tradutórias de textos técnicos sob efeito de estresse à luz do funcionalismo em tradução.
\end{abstract}

\begin{abstract}
We present perspectives to investigate psychophysiological effects on the processes of reading/writing technical texts for translation purposes under stress, following the principles of functionalism.
\end{abstract}

\section{1) Introdução}

No âmbito de uma tradutologia brasileira, verifica-se uma já longa e rica trajetória de estudos que trataram da tradução sob diferentes perspectivas. Há trabalhos mais antigos e mais recentes sobre a natureza da tradução, sobre escolhas de tradução mais e menos adequadas, sobre erros e lapsos (como Arrojo (1992) e Frota (2006)), sobre graus de expertise de tradutores e os modos como se comportam ao longo de sua leitura na língua de partida e escrita na língua de chegada (tais como Abreu (2011); Silva, Oliveira, Lima (2008)). Entretanto, excetuando-se o fator "pressão de tempo" (Campos, 2008), percebem-se lacunas no que se refere, especificamente: (1) ao processamento de uma leitura diferenciada - a leitura tradutória - que envolve uma língua estrangeira com vistas a uma escrita igualmente diferenciada; (2) ao reconhecimento da influência de fatores de estresse, especialmente de estresse laboral associado aos atuais ambientes de empresas ou de agências de tradução, sobre o desempenho dessa leitura, seja de novatos ou de experientes.

O principal objetivo deste trabalho, considerando o desenho de um plano de pesquisa de doutoramento que relaciona estresse laboral e a produção da tradução, é refletir sobre particularidades do processamento da leitura por parte de tradutores de textos técnico-científicos. Interessa também situar o conceito de uma leitura tradutória, da qual podemos observar alguns traços a partir da singularidade de uma escrita tradutora (Frota, 2000).

Assim, após apresentar um pouco do cenário de estresse laboral implicado nessa atividade, interessa-nos colocar a tradução como leitura. Em seguida, ponderamos sobre como fatores associados a estresse poderiam contribuir para gerar entraves à compreensão de leitura e consequentes inadequações na escrita do texto de chegada. Ao 
destacar a situação em que textos científicos necessitam ser traduzidos por um profissional tradutor geralmente egresso da área de Letras, refletimos também sobre um conceito que denominamos grosso modo como complexidade textual (doravante CT). A CT tende a ser associada a propriedades do texto reconhecidas como legibilidade ou leiturabilidade, temas especialmente explorados no âmbito da Psicolinguística voltada para o ensino de línguas estrangeiras (Crossley, Greenfield, \& McNamara, 2008). A CT, conforme supomos, poderia ser integrada ao quadro de fatores que podem interferir sobre a produção de leitura e de escrita do tradutor.

A pergunta que guia este trabalho, que se insere em uma pesquisa de doutorado em andamento, é a seguinte: de que maneira se poderia investigar, de modo sistemático, como fatores psicofisiológicos, tais como, por exemplo, atenção e memória, repercutem sobre o processo de leitura tradutória sob situações de estresse laboral? Naturalmente, estão envolvidos nessa questão a CT e perfis de cognição relacionada à tradução, seja como processo, seja como produto.

Este artigo está organizado da seguinte maneira: em Problemática: o texto técnico, apresentamos, em linhas gerais, nossas concepções sobre sua natureza e sobre o que há no texto técnico que empresta a ele uma complexidade especial, principalmente para a tradução. Em Como investigar a leitura tradutória sob efeitos de estresse?, são vistas questões sobre o quanto a cognição de um tradutor, sob efeito de estresse, pode influir na compreensão e produção textuais. Em Complexidade textual (CT) em breve revisão, temos uma revisão bibliográfica sobre trabalhos ou propostas, de diversas procedências, com destaque para os estudos sobre leitura que possam ser associadas de alguma forma ao tratamento do tema da CT em textos do tipo técnico ou científico. Depois, em Linguagens especializadas sob estudo, trazemos uma concepção que enfatiza o texto técnico como um todo complexo, dotado de uma complexidade que inclui e, ao mesmo tempo, transcende suas terminologias. Em Teoria funcionalista da tradução, expomos de que maneira esse tipo de texto poderia ser visto como algo que tem determinada função, uma função que deveria poder ser "reproduzida" quando de sua tradução. Partindo para Questões cognitivas e de leitura: estresse, resgatamos alguns problemas relativos à (não) precisão da leitura tradutória de profissionais no mercado de trabalho que estejam sob efeito de estresse. Por fim, em Considerações finais, descrevemos uma proposta de pesquisa, tentando colocar perspectivas teórico-metodológicas para a investigação sistematizada dessa situação.

\section{2) Problemática: o texto técnico}

No mercado de trabalho de tradução, não se trata apenas de seguir à risca normas de concordância, de pontuação, ou mesmo de se seguir um glossário de 
determinada área técnica. Há um todo significativo, no texto técnico, que é pleno de complexidades.

O profissional hoje inserido no mercado de agências de tradução, lidando com a assim chamada tradução técnica, deverá saber dividir sua atenção entre diversas coisas ao mesmo tempo: aplicativos de computador, prazos, atenção a regras e exigências de clientes, guias de estilo, etc. Isso, com sua repetição diária, pode ir montando um rico cenário de estresse, o que pode repercutir negativamente tanto sobre a leitura quanto sobre a produção textual tradutórias. Em meio a esse quadro, há que se levar em conta que tradução é atividade cognitiva de alta complexidade, em que muitas competências são ativadas. É necessário, portanto, estar-se equilibrado, concentrado. A prática mostra que isso não é tão simples de se conseguir.

Além disso, ao se trabalhar com a tradução de textos técnicos, lida-se não somente com terminologias, mas com uma organicidade linguística ímpar. Entre outros elementos, o texto técnico pode ser caracterizado por (a) uma maior busca de precisão, (b) temática específica, (c) finalidade operativa - de modo que quem o lê deverá fazer algo a partir das informações nele explicitadas, (d) tem convenções linguísticas específicas. Por ser um texto "utilitário", tem caráter altamente pragmático. É desse texto técnico "[...] que emana, diariamente, a panóplia de atividades que enformam a vida das pessoas: quer sejam atividades profissionais, escolares, ou lúdicas." (CavacoCruz, 2012, p. 11). Desse modo, desenha-se um quadro comunicativo com emissores, destinatários e situação comunicativa especializados, entre pessoas que compartilham um dado conhecimento prévio (Cavaco-Cruz, 2012, p. 14). Dotado de determinada funcionalidade na comunidade-fonte, esse texto, ao ser traduzido, deverá manter essa funcionalidade na comunidade-alvo, na medida do possível, quando da materialização tradutória.

A cognição do tradutor, uma vez afetada pelo estresse laboral, poderá afetar todo o processo de produção desse texto, culminando em um produto que apresenta falhas. Alguns problemas podem ser atribuídos, muitas vezes, a um processo de leitura prejudicado. Nesse cenário, a CT pode ser um fator a mais a "pesar" sobre o desempenho do tradutor. Essa CT, importa já situar, pode estar associada tanto a uma dada configuração lexical quanto a uma feição gramatical do texto técnico.

\section{3) Como investigar a leitura tradutória sob efeitos de estresse?}

O tradutor pode ser visto como uma espécie de leitor especializado, no sentido de que sua leitura transcende uma mera "decodificação de sinais gráficos" para apreender informações. A leitura em questão torna-se, necessariamente, aprofundada, pois implica uma compreensão, digamos, privilegiada do texto-fonte. Essa compreensão 
servirá de base para uma retextualização (conforme Travaglia (2003)).

Pode-se pensar, ao apreciar-se, por exemplo, a coletânea de O’Brien (2011), que as pesquisas sobre o aspecto fisiológico da leitura tendem a ser poucas. Além disso, em geral, ao que parece, podem não render tantos frutos quanto seriam desejados. Isso porque ainda há grande dificuldade de se detectar e analisar precisamente o que ocorre na interação olho-cérebro quando da leitura. Faz-se necessário mais pesquisa a respeito do processo de leitura. Isso em termos gerais, pensando-se na leitura como um todo, sem levarmos em conta a especificidade de uma leitura tradutória.

Afora isso, é importante frisar que a leitura não é mero automatismo de decodificação; está envolvida uma questão crucial: a de interpretar o que os "sinais" "dizem". Há, pois, um liame entre, digamos, grafologia e semântica.

Entre 1) a captura de "manchas" pela retina, 2) todo o mecanismo do olho humano, 3) o processamento dessa captura e 4) a consequente "transformação" em significado, existe um algoritmo complexíssimo; logo: "Nosso léxico é uma arena onde a competição é rude e a vantagem vai em direção aos 'habituais', isto é, às palavras mais frequentes." (Dehaene, 2012, p. 65) Ou seja: ao ler uma palavra pouco habitual que seja muito semelhante a uma mais habitual, temos maior pendor a interpretá-la como sendo essa última opção, principalmente se lemos apressadamente ou sob efeito de estresse. Isso, conforme pretendemos investigar, também pode acontecer com o tradutor de um texto técnico.

O contexto geral de toda a problemática que está envolvida em nossa proposta de pesquisa pode ser resumido como segue:

1: dado que o mercado e a profissão da tradução são cognitivamente complexos e estressantes, há falhas psicocognitivas em decorrência do trabalho;

2: ao se traduzirem textos técnicos, tem-se em mãos tarefa complexa que inclui e transcende o aspecto terminológico, chegando ao textual (e sua complexidade inerente) e ao funcional como um todo. Afinal, há uma linguagem especializada complexa que vai além do simples texto com termos, que tem determinada funcionalidade, e isso deve ser reproduzido na tradução;

3: inadequações recorrentes de tradução em textos técnicos, sejam terminológicas ou de "modos de dizer", geram sanções imediatas ao profissional, que tende a ser sumariamente excluído de equipes de trabalho;

4: faz-se necessário um melhor preparo, ou treinamento, para minimizar problemas de compreensão de leitura que possam gerar inadequações de tradução. ${ }^{1}$

Tradutores estressados, que estejam com ritmo cognitivo algo acelerado devido ao contexto atual do trabalho da tradução de textos técnicos - pressão de tempo, estresse geral em relação ao trabalho propriamente dito, pressão por desempenho ótimo em 
multitarefas, etc. - podem deixar faltar a devida atenção às tarefas de interpretação e redação inerentes à leitura tradutória. Essa falta não afetará apenas tradutores iniciantes ou novatos, ainda estudantes de tradução: profissionais de todos os níveis de experiência e proficiência estão sujeitos a esses problemas. Portanto, face à lacuna sobre esse tema nas publicações que revisamos, entendemos que se coloca um interessante ponto para pesquisas. Dito isso, trazemos algumas considerações sobre mais um aspecto relacionado ao problema levantado: a complexidade textual (CT).

\section{4) Complexidade textual (CT) em breve revisão}

Em Linguística Aplicada (LA) nacional e internacional, a complexidade textual (CT) integrou estudos sobre leitura, incluindo pesquisas sobre compreensão e estratégias de leitura, tipificação de leitores e elementos linguísticos associados a dificuldades de compreensão de leitura. Esses estudos geraram importantes contribuições, como a distinção entre complexidade informativa e complexidade linguística. Todavia, permanecem escassos, no Brasil, os trabalhos baseados em corpora, realizados com grandes extensões de dados e apoio informatizado, dedicados a reconhecer características estruturais globais de textos ou de gêneros textuais mais ou menos complexos em função das habilidades ou condições de determinados tipos de leitores. Um dos trabalhos com o qual se pode contar é, por exemplo, o de Rodrigues, Freitas e Quental (2013). Nesse trabalho, as autoras analisam, mediante o uso de ferramentas de processamento automático do português, a Coleção Literatura para Todos 1, publicada pelo MEC/SECAD. Esse material revelou grau de inteligibilidade ou de complexidade textual superior ao adequado para neoleitores, que, por definição, são (jovens, adultos e idosos) recém-alfabetizados.

Nesse sentido, vale frisar, aqui, que tradutores podem ser incluídos entre os tipos de leitores experientes, que fazem uma leitura aprofundada, distinta de uma leitura usual, com vistas à produção do texto traduzido.

$\mathrm{Na}$ bibliografia estrangeira, há registros de pesquisas sobre readability, legibilidade ou complexidade linguística, pelo menos desde os anos 1920, conforme já assinalaram Davison \& Green (1988, p. 1-4). Esses trabalhos trataram desde a compreensão de palavras até a compreensão de sentenças, chegando à compreensão que envolve o todo do texto: textos de literatura, especialmente histórias curtas ou contos para crianças e jovens. Foi contemplada inclusive a compreensão de leitura de adultos com dificuldades cognitivas ${ }^{2}$.

Sobre compreensão do texto científico ou técnico, entretanto, as referências são relativamente limitadas ${ }^{3}$. Na obra fundamental das linguistas norte-americanas Davison \& Green (op. cit.), intitulada Linguistic Complexity and Text Comprehension: 
Readability Issues Reconsidered, por exemplo, há apenas dois trabalhos dedicados a problemas de compreensão ou de acessibilidade de textos científicos ou técnicos em um nível global. Há um trabalho dedicado a uma amostra de textos operativos da Marinha da OTAN (Baker, Atwood \& Duffy, 1988). Esse trabalho tratou de trechos de manuais de instrução, os quais foram apresentados em versões originais e simplificadas para testes de compreensão com um grupo de leitores técnicos de formações diferenciadas. $\mathrm{O}$ outro trabalho que há nessa obra foi dedicado a cartas de recall de fabricantes de veículos ${ }^{4}$ (Charrow, 1988). Nele, há interessantes propostas para a elaboração dessas cartas de um modo mais acessível para um consumidor leigo.

Desde muito tempo, buscaram-se fórmulas ou modelos - sempre muito discutidos e criticados - que fossem capazes de prever quais elementos textuais estariam mais associados à dificuldade de compreensão de leitura, de modo que pudessem ser gerados, por exemplo, textos de acesso mais facilitado para uma grande fatia da população leitora. Essa população, cabe situar, correspondia a grupos sociais de escolarização recente. Entre esses estudos mais antigos de amplo espectro, não associados a uma perspectiva específica de Linguística, produzidos por volta dos anos 70, não encontramos muitas referências sobre as condições de legibilidade de textos especializados, tampouco algum trabalho que se pudesse estender à compreensão de leitura de tradutores desempenhando seu ofício.

No Brasil, um dos primeiros linguistas a se debruçar sobre o tema da leitura funcional e da maior ou menor habilidade de leitura foi Perini (1982), com o trabalho Tópicos discursivos e legibilidade (apud Fulgêncio \& Liberato, 2004, p. 9). Propunha o autor, então, que os estudantes brasileiros tivessem acesso a materiais de leitura graduados de acordo com o seu nível de escolaridade e nível de dificuldade de compreensão.

A partir do legado de trabalhos fundadores, tais como o de Perini, antes referido, Neis (1982), Kleiman (1987, 1989, 1993, 1997), Kato (1982) e Averbuck, Appel \& Hessel (1983), entre outros tantos, produzidos especialmente ao longo dos anos 80 e 90, temos hoje no Brasil um vasto e multifacetado alicerce de estudos sobre o tema da leitura. Esse corpo de conhecimento permite-nos hoje distinguir especificidades das noções de leitura, alfabetização, letramento, competência textual, competência lexical e competência leitora. Isso sem mencionarmos os inúmeros trabalhos sobre o tema da leitura na área da Educação, Ensino de Língua Portuguesa e de Línguas Estrangeiras ou de Psicolinguística. Ainda assim, permanece inexplorado o ponto da leitura dos tradutores ou mesmo da leitura dos revisores profissionais.

Nacionalmente, entre os vários trabalhos dedicados ao tema da compreensão de leitura, a partir dos anos 90, destacam-se as obras de Kleiman (1997) e de Leffa (1996). Leffa, por exemplo, já apontava que uma descrição completa do processo da 
compreensão deve levar em conta, no mínimo, três aspectos essenciais: o texto, o leitor e as circunstâncias em que se dá o encontro entre ambos. Voltaremos a essa questão mais adiante neste trabalho, sobretudo quando temos em mente as circunstâncias do trabalho profissional do tradutor de textos científicos.

No âmbito dos estudos de Leitura Instrumental ou de LSP (Language for Specific Purposes), encontra-se uma significativa produção sobre leitura e escrita de textos científicos e técnicos em língua estrangeira. Ainda que o foco de estudo sobre essa leitura seja bastante centrado em uma escrita acadêmica associada ao ensino/aprendizagem de línguas estrangeiras, há muito que se possa aproveitar para a descrição de características desses textos, mesmo que a complexidade seja um assunto um pouco incidental.

Mais recentemente, pelo menos no Brasil, com a combinação dos estudos em corpora com ensino de línguas estrangeiras, tal como vemos em Viana \& Tagnin (2010), há uma oferta de subsídios aproveitáveis, sobre leitura instrumental em língua estrangeira, para caracterizar diferentes LSPs.

Por outro lado, no cenário da Linguística Computacional ou do Processamento da Linguagem Natural, pelo menos desde os anos 60 , muito já foi e tem sido produzido sob forma de sistemas que geram versões mais simplificadas de textos, incluindo a produção de ferramentas capazes de indicar diferentes tipos de medidas de CT. Essas ferramentas também conseguem produzir diferentes tipos de representações esquemáticas do conteúdo de um texto ou de todo um corpus. Esses sistemas computacionais, de base fundamentalmente estatística, conseguem inclusive reconhecer tipologias textuais e graus de complexidade a elas associados. Um exemplo de ferramenta simplificadora, para o português do Brasil, é o sistema SIMPLIFICA, que pode ser experimentado, gratuitamente, em http://nilc.icmc.usp.br/porsimples/simplifica/.

Ainda com relação ao tema da CT, temos, em Pasqualini (2012), que seus estudos apresentam três tipos gerais de encaminhamentos:

a) centram-se em características ou elementos presentes em determinados tipos de texto e associá-los a determinadas dificuldades ou facilidades de compreensão de uma determinada categoria de leitores;

b) inferem um modus operandi do processamento mental-cognitivo de diferentes tipos de leitor mediante aplicações de testes de compreensão após ou durante diferentes tipos de experimentos de leitura com diferentes tipos de texto;

c) reúnem os indicativos dos itens a e b em prol da melhoria do ensino de leitura ou da produção materiais informativos com maior acessibilidade de compreensão leitores com proficiência de leitura reduzida ou em fase de desenvolvimento. (Pasqualini, 
Em meio a esse quadro, a questão da leitura de textos especializados é multifacetada, envolvendo diversos tipos e/ou variações de textos e de linguagens neles presentes, abarcando diferentes perfis de leitores. Entretanto, o leitor tradutor técnico, que amiúde se vê assoberbado e acaba mantendo uma relação íntima com a condição de prazos curtos, pouco aparece como tema de estudos.

Destacamos que a leitura, em nosso contexto, se trata da leitura de linguagens especializadas, realizadas em textos de complexidade singular. São textos que têm uma identidade própria e que oferecem uma dificuldade/complexidade a mais para o nosso leitor-tradutor. A seguir, trataremos de alguns aspectos implicados na rede de complexidade do texto técnico.

\section{5) Linguagens especializadas sob estudo}

Nos estudos sobre fenômenos de comunicação técnico-científica, no âmbito da Terminologia, vemos vertentes tais como a Teoria Comunicativa da Terminologia (Cabré, 1998, 1999) ou a Teoria Sociocognitiva da Terminologia (Temmerman, 2000) ${ }^{5}$. Há, porém, algumas visões "terminológicas" bastante associadas ao que se passa no ambiente do texto técnico.

Esse texto, como vemos em Azenha Jr. (1996, p. 141), é uma realidade cultural extralinguística, em que todos os níveis da hierarquia linguística presentes têm importância. Nesse cenário textual e discursivo, destacam-se os níveis "[...] grafofonológico, morfossintático e semântico, além da consideração de aspectos diretamente ligados à situação de recepção dos textos técnicos, ao contexto de comunicação e ao horizonte de valores culturais". (Idem)

Vemos, já aqui, que o tradutor tem em mãos algo de alta complexidade, mais do que um "texto com termos". Uma visão que se centra mais, nesses quesitos, no texto em si, e que também serve de base para Azenha Jr., pode ser encontrada nas reflexões de Lothar Hoffmann (2004), com sua Linguística das Linguagens Especializadas. Em seu artigo intitulado Conceitos básicos da lingüística das linguagens especializadas, Hoffmann coloca que a:

[...] terminologia é um dos traços mais claramente diferenciadores das linguagens especializadas, embora não o único. Todavia, muitas vezes não percebemos que isso nos tem conduzido a uma equiparação entre conceitos, terminologia e linguagem especializada. No âmbito dessa tripartição usual, a terminologia pertence ao vocabulário especializado. (Hoffmann, 2004, p. 85, grifo nosso) 
As terminologias padronizadas, por exemplo, visam evitar mal-entendidos, garantindo maior segurança na comunicação entre especialistas. "Essa intenção se traduz em três ações: a) alteração da língua; b) a unificação e c) a implantação." (Hoffmann, 2004, p. 86). A presença de terminologias, de diferentes tipos, relaciona-se a diferentes perfis de "complexidade textual".

Quanto a sua concepção sobre uma linguística da linguagem especializada, Hoffmann considera o trabalho terminológico apenas uma parte dessa, pois se ocupa apenas de um núcleo dessas linguagens: a terminologia (Hoffmann, 2004, p. 87). Conforme o autor:

O texto especializado é instrumento e, ao mesmo tempo, resultado da atividade comunicativa exercida em relação a uma atividade especializada sócio-produtiva. Compõe uma atividade estrutural e funcional (um todo) formado por um conjunto finito e ordenado de orações sintática, semântica e pragmaticamente coerentes (textema) ou por unidades de valor frasal que correspondem, na condição de signos lingüísticos complexos, e enunciados complexos do conhecimento humano e a circunstâncias complexas da realidade objetiva. (Hoffmann, 2004, p. 87)

Ainda:

Como qualquer outro texto, o texto especializado se caracteriza por um mínimo de sete características que conformam um padrão: a) coesão; b) coerência; c) intencionalidade; d) aceitabilidade; e) informatividade; f) situcionalidade (sic); g) intertextualidade (Beaugrande; Dressler, 1981, p. 3-11 apud Hoffmann, 2004, p. 87)

Temos particularidades distintivas em um texto especializado, graças à sua exigência de precisão na apresentação de informações; ele é distinto graças a particularidades de sua articulação. Há determinados mecanismos de coerência, de sintaxe, de léxico, de morfologia, tudo intimamente relacionado ao tipo de texto; por exemplo: "[...] manuais acadêmicos, pareceres, artigos de periódicos, orientações práticas, recensões, resumos, escrituras de patente, contratos, boletins médicos, indicações de uso, determinações de segurança do trabalho, etc." (Hoffman, 1984 apud Hoffmann, 2004, p. 88). Sobre o texto como ponto central, como arcabouço, sabe-se que:

Na visão comunicativa, o texto é o signo linguístico primário, isto é, sob condições normais, a linguagem se realiza apenas por meio de textos. E isso vale também para o texto especializado. Por isso, deve o texto, e não a palavra ou a frase, figurar como ponto central do estudo sobre linguagens especializadas. O que são lidos, traduzidos, resumidos e trabalhados de diferentes modos são os textos. Todas as outras unidades linguísticas devem ser vistas como seus constituintes, como elementos que mantêm relações diferenciadas entre si, sem as quais a textualidade não se constitui 
verdadeiramente. (Hoffmann, 2004, p. 88)

Em suma, ao se ler e traduzir um texto técnico, não basta reproduzir um rol de termos constantes em um glossário. O que se tem em mãos é um texto pleno, dotado de complexidade textual, a ser processado, trabalhado, com características ímpares relativas a cada área de especialidade. No mercado, exige-se, ainda, uma "imitação de estilo": uma complexidade a mais.

O texto técnico, com sua complexidade inerente, é composto e divulgado com determinado propósito. Esse propósito deve ser reconhecido pelos leitores-alvo desse determinado texto. Na seção a seguir, exploraremos a chamada Teoria do Escopo, que bem trata desse processo.

\section{6) Teoria funcionalista da tradução}

Analisando-se o manual de Katharina Reiss e Hans J. Vermeer (Reiss \& Vermeer, 1996), já no prólogo, entende-se que toda ação de tradução estará direcionada, de maneira mais ou menos consciente, a determinado objetivo; essa ação se realiza de tal forma que esse objetivo possa ter o maior sucesso possível na situação correspondente.

Entra em jogo, então, a capacidade de funcionamento do chamado translatum, ou o resultado da translação em certa situação. Há ação; há comportamento intencional. Leva-se em conta que toda ação depende de uma situação (seja histórica, seja de uma comunidade X, seja de uma condição social Y). Esses elementos se inter-relacionam aos interlocutores de uma interação e sua relação mútua.

Esse modelo, ou, mas apropriadamente, teoria, é conhecido(a) como Skopostheorie: em outras palavras, "teoria do escopo", sendo que "escopo" é tido como "finalidade" ou "objetivo", "para que serve". Isso tem papel fundamental em "como" funciona uma tradução - ou mesmo um texto. Pode-se asseverar que uma ação - ou uma tradução, chamada de translação/ação translativa, na teoria -, deve servir para determinado propósito. Logo, essa tem uma função. Daí chamar-se a teoria de "funcionalista". Entende-se que tradução, ou translação, não é simples reprodução linguística de um texto em outro idioma:

Uma translação é uma forma especial de interação que parte de um texto produzido anteriormente, pois, além de estar determinada pelos fatores que até agora destacamos, depende também, de certa forma, desse texto de partida e das condições de sua produção, cuja análise corresponde a uma teoria geral da produção textual. ${ }^{6}$ (Reiss \& Vermeer, 1996, p. 14) 
Há, portanto, um viés pragmático, mais voltado para a prática tradutória. Isso se entende melhor pensando-se que uma ação (ou tradução) tem um objetivo $X$, conscientemente ou não, e esse objetivo deve ser, de uma forma ou de outra, alcançado de maneira correspondente à da "origem".

O resultado de uma translação traz à tona o todo funcional que foi traduzido, não se limitando a questões linguísticas, de texto, de fidelidade a "texto". Logo: "O princípio dominante de toda translação é sua finalidade."7 (Reiss \& Vermeer, 1996, p. 80); essa finalidade - ou função - guiará as decisões do leitor-tradutor.

Embora possa surgir a ideia de fidelidade excessiva, tem-se que o escopo de um determinado texto-alvo pode ser diferente do escopo do texto-fonte. Há inclusive hierarquias de escopo (Reiss \& Vermeer, 1996, p. 86). A tradução/translação sempre se constitui em uma ação transvalorativa, no sentido de que diferentes valores terão seu lugar no texto traduzido.

Com o que foi exposto, intentamos deixar evidente que todo e qualquer texto técnico, embora tenha uma imagem geral de ser mais direto, tem uma identidade, um público-alvo, uma maneira determinada de ser lido e de ter seus significados depreendidos da maneira mais precisa possível. É dotado, pois, de uma função que deve ser reproduzida, de modo que funcione da maneira pretendida: se um texto tem a função de instruir, sua tradução deve manter essa função.

Logo, sabemos que ao se lerem e se traduzirem textos técnicos, trabalhamos com complexidade textual/linguagem especializada. Com isso, temos como objetivo depreender e reproduzir a função de um texto especializado. Por trás de toda essa complexidade, há uma mente leitora/tradutora, mente essa que se encontra vulnerável a diversos fatores, mas centramo-nos, para fins de uma proposta de pesquisa empírica, apenas em um fator: o estresse laboral.

\section{7) Questões cognitivas e de leitura: estresse}

Enxergando a leitura, em seus diferentes matizes, a partir das lentes da Psicolinguística, Psicologia, Neurologia, etc., tem-se uma atividade de grande complexidade (Frank Smith, 1989). O que se vê comumente como uma atividade simples e automática, tem grande exigência desde a aprendizagem até o leitor se tornar proficiente e maduro. Questionamo-nos, neste momento, sobre a capacidade de leitura de um leitor especializado que se vê em situação estressante. Importa lembrar que nosso contexto é de textos científico-técnicos, com presença de terminologias, e que nos concentramos na legibilidade do texto especializado.

$\mathrm{Na}$ leitura, escalamos funções várias, tais como atenção, memória, raciocínio, conhecimento de mundo: uma vez que memória e atenção são muito prejudicadas em 
situações de estresse, a leitura/compreensão do que se lê é afetada ${ }^{8}$. Isso tudo intervém na compreensão do texto escrito e em sua retextualização quando da tradução, por exemplo.

Em termos de estresse, esse é causado por qualquer coisa que nos deixe tensos, frustrados, incapazes: faz-se necessário ter habilidade para se lidar com pressões. No trabalho de tradução, por exemplo, é constante haver situações imprevisíveis, desconhecidas, inevitáveis e intensas: características essas inerentes a resoluções de problemas. A título de breve definição desse problema, temos: "Estado do organismo, após o esforço de adaptação, que pode produzir deformações na capacidade de resposta atingindo o comportamento mental e afetivo, o estado físico e o relacionamento com as pessoas." (Limongi França \& Rodrigues, 2011, p. 30).

O estresse é uma resposta produzida pelo corpo a uma situação difícil que exige adaptação; pode ou não ser negativo; é um denominador comum de adaptação do organismo às mais variadas situações. Destaque-se que organismo, naturalmente, referese também a cérebro, que, necessariamente, refere-se a mente/cognição. No caso de nosso "estresse tradutório", por exemplo, julgamos que esse penda mais para o que se chama de "distresse", ou "estresse negativo", diferente do "eustresse", ou "estresse positivo", como ocorre quando temos uma expectativa de algo bom que irá ocorrer. $\mathrm{O}$ distresse tem caráter mais patológico: é mais ou menos um sinal de que temos problemas a resolver. $\mathrm{O}$ efeito prolongado do distresse leva a mau funcionamento da cognição (atenção, memória, etc.).

Dentre alguns indicadores de agentes estressores, tem-se: queda na eficiência; insegurança nas decisões; grande nível de tensão; sentimento de frustração; desconfiança. (Limongi França \& Rodrigues, 2011, p. 50) Das falhas causadas pelo estresse, uma em particular chama-nos atenção: "Entre essas falhas, a mais prejudicial é a dificuldade, às vezes extrema, de recordação." (Izquierdo, 2002b, p. 84) Logo: "Nos últimos anos, numerosos estudos têm demonstrado de forma categórica que o estresse crônico causa a morte de neurônios justamente nas áreas do cérebro mais utilizadas para fazer ou evocar memórias." (Idem)

Para nossos propósitos, e segundo nossas observações, utilizamos "distresse" para nos referirmos ao que acomete os tradutores, distanciando-se do eustresse; em suma, um estado mental desconfortável que, como foi mencionado acima, afeta negativamente as faculdades cognitivas que bem sabemos ser utilizadas ao se trabalhar com tradução.

Dado que aqui exploramos a tradução de textos técnicos, modalidade essa plena de regras e complicações, cujo mercado é muito exigente, uma condição de estresse, por demais comum nesse contexto, arma o cenário para que ocorram problemas vários, dentre eles produção textual inadequada advinda de má leitura. 
É necessário lembrar que leitura implica também um papel ativo da parte do leitor, não apenas passivo no sentido de decodificação de sinais. Quando lemos, a leitura é ativa, não passiva: necessariamente interpretamos ativamente. Sabe-se que, na leitura, as informações são armazenadas a curto ou a longo prazos em nossa memória, que, comprovadamente, se altera funcionalmente dependendo de nosso estado emocional ${ }^{9}$.

A título de exemplo para situar o problema, relatamos algo que ocorreu conosco há não muito tempo em uma agência de tradução ao revisar o trabalho de uma colega tradutora. Determinada empresa ${ }^{10}$ estava utilizando uma tecnologia de tinta sólida para impressoras. No folheto de marketing do referido produto, rezava:

\section{Just drop, close and print!}

Ou seja, "é só soltar/largar, fechar e imprimir!". A tradutora, que, embora fosse experiente e proficiente, estava ocupada com vários trabalhos ao mesmo tempo, traduziu por:

\section{Basta pingar, fechar e imprimir!}

Sabe-se que to drop "pode" significar pingar, mas, no caso - inclusive havia uma ilustração de uma pessoa "soltando" o bastão de tinta na impressora -, a tradução estava diametralmente oposta ao esperado, ainda mais sendo o material um folheto de divulgação cujo público-alvo era os possíveis compradores do produto. Não nos cabe julgar se isso é ou não um erro crasso, mas temos segurança de que isso ocorre com muita frequência, tanto com veteranos quanto com iniciantes, mas há muito mais casos entre iniciantes. Percebe-se, em certa medida, que comumente lemos (ativamente) aquilo que está mais acessível em nossa mente. Ou seja: nossa memória parece trazer à tona o que lhe parece mais óbvio, ou o que está mais a seu alcance, quando sofre interferências de problemas tais como ansiedade ou estresse.

Quanto ao processo de leitura relacionado com a tradução - ou leitura tradutória -, interessa-nos destacar as noções de "leiturabilidade" e "legibilidade" coletadas de Resende e Souza (2011, n.p.):

É necessário, primeiramente, definir o que se entende aqui por legibilidade e leiturabilidade dos textos. Por legibilidade, compreendem-se os elementos e recursos que o próprio texto, em sua materialidade, oferece ao leitor. Trata-se da construção textual, da clareza, da coesão, do desenvolvimento e sustentação do proposto, da manutenção e respeito à função, ao público, ao veículo e aos objetivos da materialização textual verbal. A legibilidade envolve ainda aspectos físicos do texto, a exemplo das fontes escolhidas, dos espaçamentos e margens, das imagens e cores e da qualidade de impressão.

A leiturabilidade, a seu turno, se refere àquilo que o ato da leitura envolve, contemplando principalmente a função do leitor, sua competência na atividade, suas características, seus conhecimentos, seus objetivos e sua experiência. Todos estes elementos delineiam a compreensão do texto e o processo de criação de sentidos. $\mathrm{Na}$ atividade de leitura, o leitor se depara com o texto, enfrenta-o, orquestra-o, dando voz 
àquilo que ainda é silêncio.

Acredita-se que fatores internos e externos a um dado sistema podem influenciar nesses processos tanto de textos escritos em língua materna quanto estrangeira. Podem-se citar como exemplos de fatores internos: gênero, estilo, variedade linguística, sintaxe, explicitação/ocultação de informações, uso de linguagem figurada, aspectos gráficos, entre outros.

Os fatores externos referem-se aos conhecimentos prévios (linguístico, textual, enciclopédico) que o leitor possui e que são acionados na atividade de construção de sentido, aos processos de inferenciação, à competência em leitura, aos espaços de circulação do texto e à situação em que a atividade de leitura ocorre.

A compreensão de um texto é permeada pelo acesso espontâneo e não necessariamente intencional àquilo que o leitor já conhece, às suas experiências vividas, mesmo que mentalmente. É mediante a interação de diversos níveis de conhecimento de mundo que o leitor (re)elabora o sentido do texto e é justamente por isso que a leitura é um processo ativo, multifacetado, interativo e multidimensional (SOUZA, 2004; LIBERATO; FULGÊNCIO, 2007).

A leitura é um ato complexo, uma vez que ler não é atribuir sentidos ou extraílos do texto, mas é interagir com ele, ainda que o texto se constitua em objeto estático e aparentemente pronto. A compreensão textual, que pode ser o objetivo da leitura, acontece quando o leitor enfrenta o texto, usando seus conhecimentos combinados às novas informações trazidas pelo texto. (RESENDE E SOUZA, 2011, n.p.)

Além disso,

Qualquer falha que ocorra no contexto tradutório, seja na leitura do original, seja na escritura do texto traduzido, pode mudar completamente o sentido da mensagem, fazendo com que a tradução não reflita o texto de partida, obstruindo suas possibilidades de recepção (SOUTO, 2011). Portanto, o tradutor precisa estar bem preparado para perceber o que comunica o autor e reconstruir o sentido a partir de sua leitura. Estar preparado significa estar atento aos fatores que podem interferir na legibilidade ou na leiturabilidade do texto original. (REZENDE E SOUZA, 2011, n.p.)

Ou seja: de uma má leitura, independentemente das razões que a tornem inadequada, tem-se uma má textualização do que se leu/interpretou, se pensarmos em tradução. Um leitor-tradutor estressado lê mal e tem má produção textual, dado que seu processo de leitura tem certa interferência negativa ${ }^{12}$. Em Morais et al. (2004, p. 54-55), lemos: "Ler é extrair a pronúncia que corresponde a uma representação gráfica da linguagem falada. Sendo o material escrito geralmente portador de sentido, o objetivo da leitura é o de extrair esse sentido [...]". A extração do sentido daquilo que se lê, em nosso contexto, não tem a devida precisão. 


\section{8) Considerações finais}

Como lemos em Crystal (2011, p. 218-221), partindo-se de um ponto de vista científico, sabe-se muito menos sobre processos de escrita e de leitura, eis que a Linguística centrou-se mais em aspectos de fala, sendo que o interesse por questões psicológicas relativas à língua é bem mais recente. Com isso em mente, cabem alguns questionamentos:

1) Em termos psicológicos, o que faz com que acreditemos em más interpretações de leitura?

2) Quais os resultados de uma retextualização advinda de uma leitura equivocada?

3) Como se deve ler um texto técnico-científico com vistas a uma retextualização?

4) O que se pode ensinar (a tradutores) em termos de técnicas de leitura?

Além dessas perguntas, para o desenho da proposta da pesquisa em andamento, colocamos as seguintes indagações:

a) Como investigar de que maneira fatores psicológicos como atenção e memória, por exemplo, atuam no processo de leitura tradutória com fins profissionais em situações de estresse laboral?

b) Afinal, o que conforma a leitura tradutória?

c) Como se desenham as etapas metodológicas de uma investigação sobre fatores intervenientes sobre a sua qualidade do texto escrito, partindo-se do texto lido e do processo de leitura que se pode inferir?

No decorrer da pesquisa em andamento, pretendemos trazer mais dados acerca do problema de desempenho na tradução de textos técnicos e delinear possíveis maneiras de reduzi-lo. Como referenciais teóricos, amparamo-nos no modelo holístico do grupo PACTE (Hurtado Albir, 2005), na Teoria Funcionalista da Tradução (Reiss \& Vermeer, 1996) e na Linguística das Linguagens Especializadas (Hoffmann, 2004).

Para as etapas empíricas, já dispomos, como corpus, de uma série de dados por nós coletados: entrevistas com tradutores profissionais sobre sua percepção acerca de fatores de estresse laboral; um exercício de tradução produzido por alunos do curso de graduação em tradução da UFRGS, tendo sido um grupo de aprendizes submetido a fatores de estresse e outro não. Outro tipo de material, cuja análise já iniciamos, são alguns registros dos projetos SegTrad, ExpliciTrad e Expert@, coordenados pelo Prof. Fabio Alves, da UFMG. Esse material foi acessado durante visita acadêmica ao Laboratório Experimental de Tradução (LETRA) da FALE/UFMG e traz tanto desempenho de texto quanto depoimentos dos tradutores sobre suas percepções do que realizam. 
A partir de dados identificados na bibliografia e dos dados empíricos reunidos, a intenção, ao fim da pesquisa, é identificar alternativas para o treinamento ou formação de tradutores. Com essas estratégias de ensino, pretende-se se não minorar os problemas, pelo menos preparar os profissionais para perceber o cenário que facilita a presença de problemas e o perfil dos problemas mais recorrentes relacionados à leitura do texto técnico para fins de tradução.

\footnotetext{
${ }^{1}$ A pesquisa de doutoramento em andamento visa descrever percepções de sujeitos tradutores e efeitos do estresse na leitura e na produção textual tradutórias no gênero texto técnico. Os dados obtidos estão trazendo insumos quanto a possíveis maneiras de fazer com que tradutores, tanto novatos quanto expertos, sejam instruídos com relação a gerenciamento pessoal para que o problema não afete (tanto) sua produção. Foram entrevistados tradutores profissionais, realizados testes com alunos do curso de graduação em tradução da UFRGS e foram obtidos dados de pesquisa do Laboratório Experimental de Tradução (LETRA), da UFMG, com desempenho de tarefas e questionários sobre sua execução.

${ }^{2}$ Uma obra indicada pelas autoras é What makes a book readable?, publicada em 1935 (Gray \& Leary, 1935). Essa obra tentava predizer dificuldades de compreensão de leitura de adultos com algum tipo de déficit cognitivo considerando um universo de 350 livros.

${ }^{3}$ Naturalmente, há que se considerar que o texto científico só se coloca como tal, institucionalmente, a partir dos anos 1930, quando ocorre uma primeira reunião internacional de editores de textos científicos. Além disso, a leitura "técnica" ou científica só se distingue como tal à medida que haja também uma institucionalização da formação profissional, a qual gera e consome registros escritos sobre um saber e um saber-fazer.

${ }^{4}$ Interessante como esse tipo de texto atualmente tornou-se abundante no Brasil; cada vez compramos mais automóveis e já temos o anúncio de recall recorrentemente presente em jornais de circulação diária.

${ }^{5}$ Para uma visão geral, vide os manuais de Krieger \& Finatto (2004) e Barros (2004).

${ }^{6}$ Una traslación es una forma especial de interacción que parte de un texto producido con anterioridade, por lo que, además de estar determinada por los factores hasta ahora señalados, depende también de algún modo de dicho texto de partida y de las condiciones de su producción, cuyo análisis corresponde a uma teoría general de la producción textual.

${ }^{7}$ El principio dominante de toda traslación es su finalidad.

${ }^{8}$ Vejam-se Kaplan (1997) e Izquierdo (2002a), por exemplo, para se ter uma ideia de o quanto esse estado de tensão/estresse afeta as faculdades cognitivas tão necessárias para uma leitura que está muito além da leitura por prazer.

${ }^{9}$ Quanto a esse tema, recomendamos a leitura do $2^{\circ}$ capítulo de Izquierdo (2002a), intitulado Os tipos e as formas de memória, e do $6^{\circ}$ capítulo do mesmo volume: A modulação das memórias: influência do nível de alerta, do nível de ansiedade e do estado de ânimo.

${ }^{10}$ Por questão de termos assinado contrato de confidencialidade quando do trabalho, não citaremos marca ou empresa.

${ }^{11} \mathrm{Na}$ verdade, pingar seria to drip, mas levamos em conta que houve uma confusão, pois drop pode ser gotalpingo.

${ }^{12}$ No levantamento de Pickbrenner (2006, p. 26-35), por exemplo, a autora traz Leffa (1996), para quem o processo de leitura depende do enfoque dado a esse. Vemos que ler é tanto extrair quanto atribuir significados, algo de enorme importância para se ter em mente ao pensar sobre um processo como a
} 
tradução, que, além disso que foi mencionado, implica também verter significados para um texto, que tem como alvo determinado público.

\section{9) Referências bibliográficas}

ABREU, Lúcia Collischon de. (2011) "Segmentação e ritmo tradutório de tradutores expertos e novatos". Resumos. XXIII Salão de Iniciação Científica da UFRGS. Porto Alegre, 2011. Disponível em: <http://www.lume.ufrgs.br/bitstream/handle/10183/48245/Resumo_11137.pdf?sequenc e=1>. Acesso em: 17 de agosto de 2013.

ARROJO, Rosemary (org.). O signo desconstruído: implicações para a tradução, a leitura e o ensino. Campinas, SP: Pontes, 1992.

AVERBUCK, Lígia Morrone; APPEL, Myrna Bier; SILVEIRA, Rosa Maria Hessel. "Leitura: fatores que interferem na compreensão de textos no ensino de primeiro grau". Leitura. Teoria \& Prática (Campinas), Campinas, v. 1, p. 26-39, 1983.

AZENHA JR., João. "Tradução técnica, condicionantes culturais e os limites da responsabilidade do tradutor". In. Cadernos de tradução. V.1, n.1. Florianópolis, 1996.

BAKER, Eva L.; ATWOOD, Nancy K.; DUFFY, Thomas M. "Cognitive Approaches to Assessing the Readability". IN: DAVISON, Alice; GREEN, Georgia M. (eds.) Linguistic Complexity and text comprehension. Readability Issues Reconsidered. Hillsdale, Ney Jersey, London: Lawrence Erlbaum Associates, 1988.

BARROS, Lídia Almeida. Curso básico de Terminologia. São Paulo: Editora da Universidade de São Paulo, 2004.

CABRÉ, Maria Teresa. Terminology: theories, methods and aplications. Amsterdam/Philadelphia: John Benjamins Publishing Company, 1998.

"Traducción y terminología: un espacio de encuentro ineludible". In: CABRÉ, Maria Teresa. La terminología: representación y comunicación - Elementos para una teoría de base comunicativa y otros artículos. Iula/Universitat Pompeu Fabra, Barcelona, 1999.

CAVACO-CRUZ, LUIS. Manual prático e fundamental de tradução técnica. Independence: Arkonte, 2012.

CHARROW, Veda. "Readability Vs. Comprehensibility: a case study in Iproving a Real Document". In: DAVISON, Alice; GREEN, Georgia M. (eds.) Linguistic Complexity and text comprehension. Readability Issues Reconsidered. Hillsdale, Ney Jersey, London: Lawrence Erlbaum Associates, 1988, p.85-114.

CRYSTAL, David. The Cambridge encyclopedia of language. Cambridge: CUP, 2011. 
CROSSLEY, Scott. A., GREENFIELD, Jerry, \& MCNAMARA, Danielle S. (2008). “Assessing text readability using cognitively based indices". TESOL Quarterly, 42 (3), 475-493.

DAVISON, Alice; GREEN, Georgia M. (eds.) Linguistic Complexity and text comprehension. Readability Issues Reconsidered. Hillsdale, Ney Jersey, London: Lawrence Erlbaum Associates, 1988. 291p.

DEHAENE, Stanislas. Os neurônios da leitura: como a ciência explica a nossa capacidade de ler. Porto Alegre: Penso, 2012.

FROTA, Maria Paula. A singularidade na escrita tradutora: linguagem e subjetividade nos estudos da tradução, na lingüística e na psicanálise. Campinas, SP: Pontes, 2000.

"Erros e lapsos de tradução: um tema para o ensino". Cadernos de Tradução, vol. 1, $\mathrm{n}^{\mathrm{o}}$ 17. UFSC: Santa Catarina, 2006.

FULGÊNCIO, Lúcia \& LIBERATO, Yara. Como facilitar a leitura. 8 ed., São Paulo, Contexto 2004.

GRAY, Willian S.; LEARY, Bernice E. What makes a book readable? With special reference to adults of limited reading ability an initial study. Chicago: The University of Chicago Press, 1935.

HOFFMANN, Lothar. "Conceitos básicos de lingüística das linguagens especializadas". In.: In.: KRIEGER, Maria da Graça, ARAÚJO, Luzia. Cadernos de Tradução. Porto Alegre: UFRGS, nº 17, outubro-dezembro, 2004.

HURTADO ALBIR, Amparo. "A aquisição da competência tradutória: aspectos teóricos e didáticos“. (Trad. Fábio Alves) In: Pagano, Adriana; Magalhães, Célia; Alves, Fabio (orgs). Competência em tradução: cognição e discurso. Belo Horizonte: Editora da UFMG, 2005, pp. 19-57.

IZQUIERDO, Iván. Memória. Porto Alegre: Editora Artes Médicas (ArtMed), 2002a.

. Tempo de viver. São Leopoldo: Editora Unisinos, 2002b.

KAPLAN, Harold I. Compêndio de psiquiatria: ciências do comportamento $e$ psiquiatria clínica. Porto Alegre: ArtMed, 1997.

LEFFA, Vilson J. Fatores da compreensão na leitura. Projeto ELO, Ensino de línguas online: 1996. Disponível em: <www.leffa.pro.br/textos/trabalhos/fatores.pdf>. Acesso em: 20 de agosto de 2013.

"O conceito de leitura". In: LEFFA, Vilson J. Aspectos da leitura. Porto Alegre: S agra-Luzzato, 1996. p-9-24.

KATO, Mary. "Reconhecimento instantâneo e processamento". In: Série Estudos, 8, Uberaba, MG, 1982.

KLEIMAN, Ângela. "Aprendendo palavras, fazendo sentido: o ensino de vocabulário nas primeiras séries”. In: Trabalhos em Lingüística Aplicada 9. Campinas, SP: Universidade Estadual de Campinas, 1987. p. 47-81. 
Leitura: Ensino e Pesquisa. Campinas, SP: Pontes, 1989.

Oficina de Leitura teoria e prática. Campinas, SP: Pontes, 1993.

Texto e leitor: aspectos cognitivos da leitura. 5.ed. Campinas: Pontes, 1997.

KRIEGER, Maria da Graça, FINATTO, Maria José Bocorny. Introdução à Terminologia: teoria e prática. São Paulo: Contexto, 2004.

LIMONGI FRANÇA, Ana Cristina e RODRIGUES, Avelino Luiz. Stress e trabalho: uma abordagem psicossomática. São Paulo: Atlas, 2005.

MORAIS, José; KOLINSKY, Régine; GRIMM-CABRAL, Loni. "A aprendizagem da leitura segundo a psicolinguística cognitiva”. In: RODRIGUES, Cassio; TOMITCH, Lêda Maria Braga et al. Linguagem e Cérebro Humano: contribuições multidisciplinares. Porto Alegre: Artmed, 2004.

NEIS, Ignacio Antônio. "A competência de leitura". Letras de Hoje, 15 (2), 1982, p.43-57.

O'BRIEN, Sharon. (ED.). Cognitive explorations of translation. London: Continuum, 2011.

PASQUALINI, Bianca Franco. Leitura, tradução e medidas de complexidade textual em contos da literatura para leitores com letramento básico. Dissertação (Mstrado em Letras). Porto Alegre: UFRGS, 2012.

PICKBRENNER, Minka Beate. Termos compostos em língua alemã: uma contribuição para o ensino de leitura instrumental em Direito. Dissertação (Mestrado em Letras) - Universidade Federal do Rio Grande do Sul, 2006.

REISS, Katharina e Hans J Vermeer. Fundamentos para una Teoría Funcional de la Traducción. Madrid: Akal, 1996.

RESENDE, Nair Rodrigues \& SOUZA, Ana Cláudia de. "A atividade tradutória e a relevância da leitura: legibilidade e leiturabilidade de textos humorísticos traduzidos". Revista Gatilho. Ano VII, Volume 13, setembro de 2011. Juiz de Fora, MG: UFJF. Disponível em: <http://www.ufjf.br/revistagatilho/files/2011/10/resende.pdf>. Acesso em 5 de junho de 2012.

RODRIGUES, Erica dos Santos; FREITAS, Cláudia; QUENTAL, Violeta. "Análise de inteligibilidade textual por meio de ferramentas de processamento automático do português: avaliação da Coleção Literatura para Todos". Letras de Hoje, Porto Alegre, v. 48, n. 1, p. 91-99, jan./mar. 2013. Disponível em: < http://revistaseletronicas.pucrs.br/ojs/index.php/fale/article/viewFile/12048/8886>.

Acesso em: 14 de novembro de 2013.

SILVA, Igor Antônio Lourenço da, OLIVEIRA, Maria Luisa de, LIMA, Kelen Cristina Sant'Anna. "Conhecimento experto em tradução: uma abordagem processual e discursiva de tarefas tradutórias realizadas por pesquisadores expertos". Revista ABRALIN, vol. 7, $\mathrm{n}^{\mathrm{o}}$ 1, 2008. Disponível em: 
$<$ http://www.abralin.org/revista/rv7n1/12-Igor-Antonio.pdf $>$. Acesso em: 13 de agosto de 2013.

SMITH, Frank. Compreendendo a leitura: uma análise psicolingüística da leitura e do aprender a ler. Porto Alegre: Artes Médicas, 1989.

TEMMERMAN, Rita. Towards new ways of terminology description. The sociocognitive approach. Amsterdam/Philadelphia: John Benjamins Publishing Company, 2000.

TRAVAGLIA, Neusa G. Tradução e Retextualização. Uberlândia: EDUFU, 2003.

VIANA, Vander; TAGNIN, Stella E. O. (orgs.). Corpora no ensino de línguas estrangeiras. São Paulo: HUB Editorial, 2010. 